\title{
A práxis filosófica no Proeja: reflexões sobre as relações sociais capitalistas e a formação humana integral
}

\section{Philosophical praxis in Proeja: reflections on the social capitalist relations and integral human formation}

\author{
Elieser Toretta Zen* \\ Edna Castro de Oliveira**
}

\begin{abstract}
RESUMO
Este trabalho resulta de pesquisa concluída que teve como objetivo analisar a práxis filosófica de estudantes e docentes de uma turma do Curso de Segurança do Trabalho (CST) a partir do exercício crítico sobre as relações sociais capitalistas, como atitude filosófica que integra as dimensões técnica e humanística da formação humana. O problema investiga a constituição de uma práxis filosófica em algumas disciplinas de uma turma do CST e as possibilidades desta se configurar como espaço de desenvolvimento da formação humana integral de estudantes e professores. $\mathrm{O}$ aporte teórico teve no materialismo histórico-dialético suas bases por meio de diálogos entre Marx, Gramsci e Freire. A opção metodológica assumida foi pela pesquisa participante que envolveu o pertencimento à comunidade e o diálogo entre os sujeitos. Participaram 12 alunos e sete docentes de uma turma do CST nos períodos de 2014/2 e 2015/1; duas alunas do último período, totalizando assim 14 alunos e sete docentes. Os resultados revelaram que, por meio da práxis filosófica, os sujeitos exercitaram o diálogo crítico acerca das desigualdades sociais. Revelou que a práxis filosófica, só conseguiu realizar a
\end{abstract}

* Instituto Federal de Educação, Ciência e Tecnologia do Espírito Santo. Programa de Mestrado Profissional de Ensino de Humanidades. Vitória, Espírito Santo, Brasil. E-mail: elieserzen@ hotmail.com. ORCID: https://orcid.org/0000-0002-4705-1636

** Universidade Federal do Espírito Santo. Programa de Pós-Graduação do Centro de Educação. Vitória, Espírito Santo, Brasil. E-mail: oliveiraedna@yahoo.com.br. ORCID: https://orcid. org/0000-0003-0798-7090 
dimensão integradora entre as áreas de conhecimento, porque a filosofia é fundamento e guia da ciência, ao mesmo tempo, em que é guiada por ela. Explicitou a relação dialética entre filosofia e ciência, entre o pensamento e ação, contribuindo para um processo de formação humana integral no Proeja.

Palavras-chave: Práxis filosófica. Relações sociais capitalistas. Proeja. Formação humana integral.

\begin{abstract}
This work aimed to analyze the philosophical praxis of students and teachers of a class of the Work Safety Course (CST) from the critical exercise on the social capitalism relations, as a philosophical attitude that integrates the humanistic and technical dimensions of the human formation. It investigated the possibilities to consider philosophy as a praxis in the integral human formation of students and teachers. The theoretical background was based on the historical dialectical materialism established by the dialogues among Marx, Gramsci and Freire. This participatory research involved being part of a certain community and the dialogue among the subjects. Twelve students and seven teachers from a CST group participated in the 2014/2 and 2015/1 periods; Two students from the last period, totaling 14 students and seven teachers. The results revealed that students and educators had a critical attitude towards social inequalities. They also revealed that philosophy has only been able to consolidate the integrative dimension between the areas of knowledge, for it is the foundation and guide of science, while it is guided by it. Thus, the dialectic relationship between philosophy and science, between thought and action, was explained, contributing to a process of integral human formation in Proeja.

Keywords: Philosophical praxis. Social capitalist relations. Proeja. Integral Human Formation.
\end{abstract}

\title{
Introdução
}

O trabalho é parte integrante de pesquisa de doutorado concluída que teve como objetivo analisar a práxis filosófica de estudantes e professores de algumas disciplinas de uma turma do Curso de Segurança do Trabalho (CST) do Proeja (Programa Nacional de Integração da Educação Profissional com a Educação Básica na modalidade Educação de Jovens e Adultos) a partir do exercício do diálogo crítico, como atitude filosófica que integra as dimensões 
técnica e humanística da formação humana. Com essa ênfase, o trabalho busca refletir sobre as possibilidades de uma práxis filosófica no Proeja, em específico no Curso de Segurança do Trabalho, que contribua para a formação humana integral de jovens e adultos trabalhadores. Com essa premissa, defendemos, neste trabalho, que a práxis filosófica na turma do curso pesquisado se evidencia como elemento integrador entre alguns componentes curriculares, pelo exercício do diálogo crítico, em torno das relações sociais capitalistas e suas implicações na conformação e/ou transformação da realidade pessoal e social tendo em vista a formação humana integral no Proeja.

Como convite à leitura deste trabalho, importa indicar que está organizado em três momentos, além das considerações finais. Assim, no primeiro momento, procuramos problematizar a formação humana à luz da filosofia desenvolvida por Marx, Gramsci e Freire, por meio dos quais buscamos os fundamentos teóricos que dão sustentação à concepção de formação humana integral. Nesse momento, trazemos a lume algumas categorias presentes no pensamento desses filósofos que consideramos fundamentais para problematizar a formação humana integral no Proeja, com destaque para as categorias, trabalho, formação omnilateral e práxis. No segundo momento, explicitamos o aporte teórico-metodológico do estudo, destacando, o método da análise de conteúdo como ferramenta para a análise e interpretação dos dados da pesquisa de campo. Explicitamos a natureza da pesquisa bem como o universo do estudo e a abordagem metodológica do trabalho de campo, a pesquisa participante. No terceiro momento, exploramos alguns diálogos produzidos no movimento de inserção na pesquisa de campo à luz do aporte teórico que serviu de base à pesquisa. Para tanto, procuramos analisar algumas categorias que emergiram nas aulas de algumas disciplinas e nas entrevistas com estudantes e professores, em específico os temas do trabalho terceirizado, desemprego e o processo de formação humana integral no Proeja.

\section{Os fundamentos teóricos da formação humana integral: Marx, Gramsci e Freire}

A perspectiva teórica a partir da qual procuramos refletir criticamente sobre a formação humana integral, no Proeja, tem no pensamento de Marx, Gramsci e Freire suas principais referências. Assim, buscamos na filosofia desenvolvida por Marx (2002, 2015), Gramsci $(1978,1982)$ e Freire $(1987,2013)$, os fundamentos teóricos que nos ajudaram a refletir sobre essa concepção. Desse modo, aprofundamos no decorrer da pesquisa algumas categorias presentes 
no pensamento desses filósofos, tais como: trabalho, alienação e emancipação humana em Marx; escola unitária e formação humana omnilateral em Gramsci; práxis, conscientização e libertação em Freire. Fundamentados em Marx (2002, 2015) trouxemos a lume o duplo sentido do trabalho, ontológico e histórico. Para Marx, o sentido ontológico do trabalho reside em ser uma atividade vital no processo de formação integral do homem. Portanto, para se formar como ser propriamente humano, necessita se objetivar e se apropriar da natureza que lhe é exterior. Suas forças essencialmente humanas, ou seja, seus sentidos materiais e espirituais só se tornam especificamente humanos nesse intercâmbio. Assim, a reprodução das condições objetivas que assegure a satisfação das necessidades humanas é o primeiro ato de toda a história humana "que ainda hoje, tal como há milhares de anos, tem de ser realizado dia a dia, hora a hora, para ao menos manter os homens vivos" (MARX; ENGELS, 2009, p. 41).

Por conseguinte, o trabalho possibilita o salto ontológico ${ }^{1}$ do animal para o humano, do ser meramente animal para o ser social. O trabalho, portanto, é a mediação entre o ser humano e a natureza, é princípio ontológico fundamental no processo de formação humana. Para Marx (2013) o sentido histórico do trabalho advém do fato de que em cada formação social o trabalho adquiriu significados específicos. Por exemplo, nas relações sociais capitalistas com a divisão social e técnica do trabalho, engendrou-se a alienação do trabalhador. Esta divisão gerou a unilateralidade, uma vez que restringiu e limitou o desenvolvimento e a formação do trabalhador. Nas relações sociais capitalistas, o trabalho se converteu em um objeto estranho e desumano ao ser do trabalhador, um fetiche, que não possibilita a formação humana integral do trabalhador. Em contraponto ao trabalho alienado, a formação humana integral significa desenvolvimento total, completo, em todos os sentidos, das potencialidades e das forças produtivas e espirituais do trabalhador. Por certo, uma formação omnilateral depende da existência de relações sociais não alienadas entre os seres humanos e a natureza, o que só será possível com a supressão das relações sociais capitalistas e da construção da sociedade comunista, que possibilitará “"[...] a reintegração, ou o retorno do homem a si mesmo, como a eliminação da autoalienação do homem" (MARX, 2002, p. 137). Nessa perspectiva "o homem apropria-se do seu ser omnilateral de uma maneira compreensiva, portanto como homem total" (MARX, 2002, p. 141).

1 Exatamente em virtude disso [...] "com o trabalho, portanto, dá-se ao mesmo tempo, no plano ontológico, a possibilidade do desenvolvimento superior dos homens que trabalham" (LUKÁCS, 1979, p. 16). 
Buscamos também, na filosofia da práxis ${ }^{2}$ desenvolvida por Gramsci (1978, 1982), os fundamentos teóricos para problematizar criticamente as relações sociais capitalistas e a formação humana integral. Com efeito, na esteira do pensamento marxiano Gramsci retoma e aprofunda a concepção de formação humana omnilateral. No que tange à atitude filosófica, Gramsci $(1978,1982)$ não compreende a filosofia como mera especulação do mundo, como um saber abstrato, sem nenhuma utilidade, mas como saber que nasce por meio da práxis social, e o filósofo como um ser concreto e comprometido com a crítica e transformação sociedade. Desse modo, Gramsci $(1978,1982)$ critica a concepção do intelectual como ser separado das relações sociais e de que o trabalho intelectual não comporta o manual. Para o filósofo sardo, não é a natureza da atividade intelectual ou manual que traz em si mesma o caráter dual, mas é o lugar que ela ocupa nas relações sociais que acarretará valorização ou não da atividade no seio das relações de produção da vida material e, por conseguinte, a dicotomia entre ambas.

Dessa feita, em Americanismo e fordismo (2008), o filósofo italiano, ao analisar o desenvolvimento da indústria, argumenta que ela, ao requerer novos métodos de produção, demanda mudanças nas formas de organização do trabalho e da própria atividade teórico-prática do trabalhador. Nesse contexto, está claro para Gramsci que os industriais não se preocupam com o desenvolvimento espiritual do trabalhador, mas ao mesmo tempo, é por meio da indústria, da criação produtiva, que "a humanidade e espiritualidade pode realizar-se [...] quando a personalidade do trabalhador se refletia completamente no objeto criado [trabalho não alienado], quando ainda era forte a ligação entre arte e trabalho" (GRAMSCI, 2008, p. 67). Assim, em toda atividade humana, qualquer que seja, há um vínculo entre as dimensões física e intelectual, prática e teórica, ação e pensamento, de forma que não é possível, sob pena, de desintegração e aniquilamento do ser do trabalhador, separar a atividade manual da atividade intelectual. Nesse sentido, é que o filósofo italiano tece crítica contundente à escola quando esta reproduz a separação entre trabalho intelectual e manual engendrada pelas relações sociais capitalistas de produção, e que separa o saber do fazer, a concepção da execução, o trabalho complexo do trabalho simples, o profissional do cidadão. Portanto, deve-se, no entender de Gramsci, evitar a separação entre escola profissional e escola humanista, criando-se, ao contrário, um tipo único de escola que prepare os jovens, formando-os omnilateralmente. Assim, o modelo de escola profissional de sua época (não diferente de hoje) cumpria e cumpre a função de

2 "A filosofia da práxis é aquela que faz do trabalho sua categoria central, por isso seu objeto não é o ser em si, mas o ser constituído pela atividade humana real, ou seja, o ser social" (VÁZQUEZ, 2002, p. 174). 
eternizar as desigualdades de classes e o trabalho alienante, sob falsos princípios democráticos. Em outras palavras, a escola não deveria ser imediatamente interessada, oposta àquela aristocrática, considerada, por ele, interessada por servir a uma minoria de privilegiados, por destinação de família. Por isso, para o pensador italiano, essa escola aparentemente desinteressada tinha de fato um interesse imediato, que era formar a elite dirigente "[...] que não deveria pensar em se preparar para um futuro profissional, [e a difusão] cada vez mais de escolas profissionais especializadas" (GRAMSCI, 1982, p. 110) destinadas aos filhos das classes trabalhadoras. Com efeito, o adjetivo interessado, atribuído por Gramsci, opõe-se a desinteressado, que comporta um horizonte amplo, de longo alcance, isto é, que interessa objetivamente não apenas a indivíduos ou a pequenos grupos, mas à coletividade e até à humanidade inteira. Desse modo, a expressão "desinteressada" não quer dizer neutro ou indiferente. Pelo contrário, na concepção gramsciana uma escola "desinteressada" significa que ela tem a função de contribuir para uma formação integral dos trabalhadores.

Em Freire (1987), encontramos fundamentos teóricos da formação humana integral que atravessam seu pensamento. Nessa perspectiva, pode-se refletir sobre suas contribuições (1987) a partir da "investigação temática" pela qual os educandos da EJA - Educação de Jovens e Adultos procuram em seu universo vocabular e nas relações sociais as palavras e temas centrais de seu percurso formativo, por exemplo, o tema do trabalho terceirizado, que será objeto de análise neste texto. Na verdade, a conscientização como ápice do processo educativo implica a coexistência contraditória de diferentes formas de consciência, o que significa uma relação dialética entre os diferentes modos de consciência tematizados inicialmente por Freire. Assim, entendemos que em Freire a conscientização é uma das dimensões da formação humana integral. É um processo permanente em que o educando é desafiado a desenvolver um pensamento crítico frente à realidade, como prática da liberdade, fundada no diálogo, como essência de uma educação libertadora. A práxis filosófica comprometida com a formação humana integral deve possibilitar o diálogo dos educandos consigo mesmos, com o outro, com sua realidade existencial e com os problemas de seu tempo. Certamente, a conscientização, compreendida como práxis, é um processo de ação e reflexão, ou seja, de humanização de si e do mundo. Um movimento de busca de "ser mais" como possibilidade histórica de transformação de si, de luta social para a construção de uma nova sociedade e de um novo ser humano. Assim, “[...] a conscientização não pode existir fora da práxis, ou melhor, sem o ato ação-reflexão" (FREIRE, 2001, p. 30). Para Freire os seres humanos, ao agirem sobre o mundo, “[...] criam o domínio da cultura e da história, da práxis que, sendo reflexão e ação verdadeiramente transformadora da realidade, é fonte de conhecimento reflexivo e criação" (FREIRE, 1987, p. 92). 
Por conseguinte, no construto teórico freireano a categoria práxis ${ }^{3}$ relaciona-se à categoria trabalho desenvolvida por Marx e Gramsci e contribui para um processo de formação humana integral como movimento de humanização do mundo e do homem. Para esses filósofos, é pelo trabalho que o homem transcende a realidade e transforma a natureza externa, imprimindo-lhe uma marca especificamente humana. Por meio do trabalho e da práxis compreende-se que somente o ser humano é capaz de produzir a própria existência. Para Freire, o modo de produção capitalista tem desumanizado homens e mulheres, distorcendo sua vocação ontológica de "ser mais", de humanizar-se. Por isso, uma práxis filosófica que se contraponha à alienação da vida social e individual envolve momentos dialeticamente imbricados de crítica e autocrítica, de prática e teoria, de ação e reflexão. Nessa perspectiva, "[...]. uma de nossas tarefas, como educadores e educadoras, é descobrir o que historicamente pode ser feito no sentido de contribuir para a transformação do mundo" (FREIRE, 1993, p. 36).

\section{A perspectiva metodológica e os sujeitos participantes da pesquisa}

A opção metodológica pela pesquisa participante foi assumida no processo. Essa se realizou tomando por base o pertencimento à comunidade, a participação e o diálogo entre os envolvidos. Os sujeitos participantes da pesquisa foram 12 estudantes e sete (7) professores de uma turma do CST em que nos inserimos atuando com a observação participante nos períodos de 2014/2 e 2015/1; participaram ainda duas estudantes do último período do CST, totalizando assim 14 estudantes e sete (7) professores. Como características da pesquisa participante, presentes no desenvolvimento da investigação destacaram-se: interação e diálogo entre estudantes, professores e pesquisadores durante as aulas e entrevistas. No segundo semestre letivo 2014/2, realizamos a observação participante que envolveu o registro em áudio de sete componentes curriculares, com quantidade de aulas diferenciadas para cada disciplina, tendo "Filosofia II" e "Física II" carga horária de duas aulas por semana; "Língua Portuguesa III", "História III", "Técnicas de Didática e Pesquisa" e "Matemática III" três aulas semanais e por fim, "Direito Aplicado" quatro aulas semanais.

No semestre letivo de 2015/1 passamos a participar das aulas de "Psicologia do Trabalho", "Sociologia II" e "Estatística Aplicada" para participar,

3 Nesse sentido "[...] a práxis é reflexão e ação dos homens sobre o mundo para transformá-lo. Sem ela, é impossível a superação da contradição opressor-oprimido" (FREIRE, 1987, p. 38). 
observar e registrar em áudio as aulas. O movimento de interpretação e análise dos dados obtidos na pesquisa de campo foi feito por meio da ferramenta da análise de conteúdo. Assim, tomando-se por base os estudos de Bardin (1977) e de Franco (2005) compreendemos a análise de conteúdo como uma ferramenta de pesquisa situada de forma ampla na comunicação, tendo por base a mensagem. $\mathrm{Na}$ fase preparatória ou exploratória, buscamos selecionar e organizar o material, para decompô-lo e depois recompô-lo, fazendo emergir seus significados. Assim, uma das primeiras tarefas assumidas foi a de efetuar um recorte dos conteúdos das aulas em elementos, para, em seguida, ordená-los em categorias (LAVILLE, DIONNE, 1999, p. 216).

Inicialmente os dados se apresentaram na forma bruta, assistemática, como conjunto caótico e, aos poucos, ganharam forma, na medida em que foram sendo sistematizados e refinados. Portanto, na fase de pré-análise, organizamos os dados produzidos e coletados no movimento de inserção da pesquisa de campo, concatenando-os para posterior seleção e categorização. Tendo superado a fase de "pré-análise", bem como a organização do material e a seleção e recorte dos conteúdos das aulas, passamos à "exploração do material", a fase mais longa e complexa, com a classificação e codificação das fontes e o "tratamento dos resultados", por meio da inferência e interpretação dos conteúdos, que correspondem à última e fundamental fase da análise do conteúdo. Com efeito, de acordo com Bardin (1977), é nessa fase que são feitos recortes em "unidades de contexto e unidades de registro", requisitos para uma boa categorização e exclusão mútua, homogeneidade, pertinência, objetividade e fidelidade.

\section{A práxis filosófica no Proeja: reflexões sobre as relações sociais capitalistas e a formação humana integral}

Nesta última parte do texto, trazemos à reflexão, com base na ferramenta da análise de conteúdo (BARDIN, 1977), alguns diálogos críticos entre estudantes e professores ao problematizarem alguns temas presentes nas relações sociais capitalistas. Como vimos, Marx, Gramsci e Freire desenvolveram uma filosofia crítica do sistema capitalista. Como filósofos da práxis, e a partir do contexto dos séculos XIX e XX, refletiram criticamente sobre as relações sociais capitalistas, bem como dedicaram o melhor de seus esforços para a superação da ordem capitalista. Assim, na esteira do pensamento dos filósofos da práxis, exercendo uma atitude filosófica crítica sobre o sistema capitalista, em aula de "Sociologia II", uma educanda assim se expressou: "[...] se eu estou me fartando 
e alguém do lado está passando fome, há algo de errado, de injusto. Quem são os milionários do Brasil?" (ZILDA ARNS, educanda).

Assim, a educanda explicita uma atitude crítica ao sistema que busca acumular riqueza para poucos e produzir miséria para grande parcela da humanidade. Não poderia ser diferente "num modo de produção em que o trabalhador serve às necessidades de valorização do capital em vez de a riqueza objetiva servir às necessidades de desenvolvimento do trabalhador" (MARX, 2013, p. 697), o que se configura como ação contrária à ética compreendida como socialização dos bens a serviço de uma vida digna para todos. Em oposição à idolatria do capital, do ter que ofusca e nega o ser, se ergue a "ética universal do ser humano [...] de sua vocação ontológica para o ser mais, como de sua natureza constituindo-se social e historicamente" (FREIRE, 1997, p. 20). Em sintonia com essa perspectiva, educandos e educador, em aula de "Sociologia II", problematizaram de forma crítica o trabalho terceirizado como manifestação do trabalho alienado e a necessidade de superação dessa lógica, como condição ontológica e histórica de humanização das classes trabalhadoras, como exposto no quadro a seguir (Quadro 1):

Os diálogos do Quadro 1 evidenciam que os educandos e educadora, ao problematizarem o tema da "terceirização" desenvolveram sobre ele uma atitude filosófica crítica e propositiva. O relato da educanda é muito significativo, pois além de uma compreensão crítica do fenômeno da terceirização, traz sua vivência como trabalhadora terceirizada, inserida nas relações sociais de trabalho no modo de produção capitalista. $\mathrm{O}$ trabalhador terceirizado, além de receber um salário menor em relação ao trabalho não terceirizado, geralmente tem uma jornada de trabalho maior do que o trabalhador não terceirizado. Assim, o aumento da jornada de trabalho do trabalhador terceirizado em relação ao não terceirizado faz parte da "[...] sede vampírica por sangue vivo do trabalho. Apropriar-se de trabalho 24 horas por dia é, assim, o impulso imanente da produção capitalista" (MARX, 2013, p. 329). Por certo, a expressão mais atual e dramática, do ponto de vista da regressão social que estamos vivendo, da supremacia e mundialização do capital, de sua busca desesperada por aumentar os lucros, da precarização estrutural do trabalho e da destruição de direitos das classes trabalhadoras, é a terceirização (ANTUNES, DRUCK, 2014). 
QUADRO 1 - AULA DO COMPONENTE CURRICULAR “SOCIOLOGIA II”

\begin{tabular}{|c|c|}
\hline Componente curricular & Sociologia II \\
\hline & $2 / 6 / 2015$ \\
\hline Tema da aula & Terceirização \\
\hline Categorias & Trabalho \\
\hline Subcategorias & $\begin{array}{l}\text { Capitalismo, terceirização, direitos dos trabalhadores e } \\
\text { socialismo. }\end{array}$ \\
\hline Unidades de registro & $\begin{array}{l}\text { O trabalhador terceirizado perde vários direitos trabalhistas. } \\
\text { Nas empresas terceirizadas ocorrem mais acidentes de trabalho } \\
\text { e o salário é menor. A terceirização é o vilipêndio total dos di- } \\
\text { reitos do trabalhador. Se aprovada a PEC 4330, os trabalhadores } \\
\text { vão regressar às condições de trabalho análogas à escravidão, } \\
\text { como na época da Revolução Industrial. }\end{array}$ \\
\hline $\begin{array}{l}\text { Unidades de contexto } \\
\text { (participação de } \\
\text { estudantes) }\end{array}$ & $\begin{array}{l}\text { Zilda Arns": As empresas arrancam muito. Por exemplo, se o } \\
\text { trabalhador terceirizado sofrer um acidente, não tem direito de } \\
\text { recorrer ao INSS, a férias e ao FGTS. Isso é um direito do traba- } \\
\text { lhador que é arrancado. Independentemente de ser trabalhador } \\
\text { terceirizado, ele tem esse direito, mas só que é roubado dele. } \\
\text { Eu já trabalhei por muito tempo na terceirizada e não temos os } \\
\text { mesmos direitos dos trabalhadores de carteira assinada, como } \\
\text { vimos na aula de direito. Se ocorrer um acidente dentro da em- } \\
\text { presa, o trabalhador terceirizado não tem o mesmo direito. Ah, } \\
\text { você me fez lembrar aquela música, "está vendo aquele edifício, } \\
\text { moço?", de Zé Geraldo. } \\
\text { Celia Sánchez: Eu sou totalmente a favor do socialismo. Ser } \\
\text { socialista é querer uma igualdade. É querer que as pessoas ti- } \\
\text { vessem qualidade plena nos seus direitos. É não querer só para o } \\
\text { outro ou só para mim. É querer que todos tivessem seus direitos } \\
\text { garantidos de forma igualitária. }\end{array}$ \\
\hline $\begin{array}{l}\text { Unidades de contexto } \\
\text { (participação do } \\
\text { professor) }\end{array}$ & $\begin{array}{l}\text { Nise da Silveira: O capitalismo nasce concentrando riqueza nas } \\
\text { mãos de uma minoria e produzindo miséria para grande parte } \\
\text { da humanidade. Então, essa música que você falou, do Zé Ge- } \\
\text { raldo, nos diz da necessidade de socializar a riqueza, o que para } \\
\text { mim só seria possível em uma sociedade socialista. Em uma } \\
\text { sociedade igualitária, uma sociedade justa, diferente da socie- } \\
\text { dade capitalista em que o trabalhador trabalha, produz riqueza, } \\
\text { mas é pobre. }\end{array}$ \\
\hline
\end{tabular}

*Os nomes dos estudantes e professores participantes da pesquisa foram substituídos por nomes de lutadores do povo.

FONTE: Elaborado pela autoria.

De acordo com Antunes e Druck (2014), uma visão crítica desse fenômeno, como a manifesta pelos educandos e educadora, revela que as empresas terceirizam como forma de reduzir os custos com a força de trabalho humana 
bem como de transferir os riscos de acidentes de trabalho para os trabalhadores e proceder a uma brutal exploração. Por isso, o resgate da dimensão ontológica do trabalho, como proposto por Marx, Gramsci e Freire, requer, em última análise, a crítica e superação do trabalho alienado posto em prática nas relações sociais capitalistas. Somente assim, a formação humana integral do trabalhador será desenvolvida, pois que o "homem rico é ao mesmo tempo o homem que precisa de uma soma de manifestações humanas; é aquele cuja realização existe como urgência natural interna, como necessidade" de tal forma que no socialismo a riqueza e a pobreza adquirem "um significado humano e, assim, social. A pobreza é o laço paciente que leva o homem a sentir como necessidade a maior riqueza, os outros homens" (MARX, 2002, p. 146, grifos do original).

Em seu relato, uma das educandas, argumenta que somente admitindo-se a igualdade substantiva como pressuposto das relações humanas, é que se poderá alcançar uma sociedade justa em que todos tenham acesso aos bens necessários a uma existência verdadeiramente livre e digna, ou seja, "numa sociedade revolucionária, que visa ao socialismo, [...] uma sociedade de trabalhadores" (FREIRE, 1978, p. 129), emancipados. Nesse sentido, os diálogos entre docente e discente, em interface com os dados analíticos, sinalizam para uma práxis filosófica crítica que visa à transformação das relações sociais capitalistas, tendo como horizonte a formação humana integral no Proeja. Por conseguinte, compreendemos que essa se faz fundamental no processo de formação humana, pois que, segundo Freire (2013, p.106-107), "aspira a mudanças radicais na sociedade, no campo da economia, das relações humanas, da propriedade, do direito ao trabalho, à terra, à educação, à saúde" sem pretender reduzir a formação humana aos aspectos tecnicistas, mantendo intocada a ordem social injusta do capital. Nesse sentido, trazemos os diálogos entre educador e educando, transcorridos na aula de "História III", conforme o quadro a seguir (Quadro 2).

Assim, os diálogos sinalizam para uma atitude crítica do "discurso cinicamente fatalista neoliberal que proclama ser o desemprego no mundo uma desgraça do fim de século" (FREIRE, 2013, p. 123). Ao contrário, o desemprego faz parte do modus operandi do sistema capitalista, que produz o desemprego estrutural, excluindo os trabalhadores do direito e do dever do trabalho, como atividade vital no processo de transformação e humanização de si e do mundo. Assim, um exército industrial de reserva disponível se torna necessário ao processo de "acumulação ou do desenvolvimento da riqueza com base capitalista. Essa superpopulação se converte, em contrapartida, em alavanca da acumulação capitalista, e até mesmo numa condição de existência do modo de produção capitalista" (MARX, 2013, p. 707). Em síntese, retomando os diálogos referentes às aulas, conforme delineado anteriormente, pode-se reafirmar que educandos e educadores desenvolveram uma práxis filosófica, por meio de uma atitude 
crítica em relação ao fenômeno do desemprego, situando-o não como "uma fatalidade, [mas antes como] resultado de uma globalização da economia e de avanços tecnológicos a que vem faltando o dever ser de uma ética realmente a serviço do ser humano e não do lucro" (FREIRE, 2013, p. 127).

QUADRO 2 - AULA DO COMPONENTE CURRICULAR "HISTÓRIA III"

\begin{tabular}{|c|c|}
\hline Componente curricular & História III \\
\hline $\begin{array}{c}\text { Data } \\
\text { Tema da aula }\end{array}$ & $\begin{array}{l}\text { 3/3/2015 } \\
\text { Apresentação do conto "Trabalhadores da estiva", de João do Rio. }\end{array}$ \\
\hline Categorias & Trabalho \\
\hline Subcategorias & Trabalho, capitalismo, tecnologia e direitos sociais. \\
\hline Unidades de registro & $\begin{array}{l}\text { A literatura pode ser um caminho e um meio que nos ajuda a } \\
\text { compreender de forma crítica a realidade do trabalho. A legisla- } \\
\text { ção trabalhista não surgiu da boa vontade dos exploradores dos } \\
\text { trabalhadores, mas nasceu da própria organização dos trabalha- } \\
\text { dores lutando por direitos. }\end{array}$ \\
\hline $\begin{array}{l}\text { Unidades de contexto } \\
\text { (participação de } \\
\text { estudantes) }\end{array}$ & $\begin{array}{l}\text { Zilda Arns: Hoje em dia, na minha visão, vejo isto: tudo o que } \\
\text { ameaça o capitalismo eles vêm e destroem. Na realidade, tudo o } \\
\text { que ameaça o capitalismo é perseguido e destruído. } \\
\text { Helen Keller: A máquina está substituindo o ser humano, não é } \\
\text { mesmo? } \\
\text { Gandhi: As pessoas saem da roça e vêm para a cidade e não têm } \\
\text { direito a nada, ficam desempregadas, sem casa e sem comida. }\end{array}$ \\
\hline $\begin{array}{l}\text { Unidades de contexto } \\
\text { (participação do } \\
\text { professor) }\end{array}$ & $\begin{array}{l}\text { Mandela: Nós, cidadãos, temos o direito de participar da produ- } \\
\text { ção e da riqueza nacional. O emprego, por exemplo, a política do } \\
\text { emprego, é uma política que tem que atender a todos, não pode } \\
\text { ser uma política de desemprego. Assim, se é necessário reduzir } \\
\text { a jornada de trabalho de todo mundo, vamos reduzir, para gerar } \\
\text { emprego para todo mundo. O capitalismo não precisa de mão de } \\
\text { obra, o agronegócio não precisa de mão de obra. A tecnologia é } \\
\text { apropriada pelo capital e serve para acumular mais riquezas, por } \\
\text { exemplo, uma máquina colheitadeira de cana substitui oitenta } \\
\text { homens, quer dizer, você passa a máquina, sai colhendo, joga no } \\
\text { caminhão, leva e faz o álcool. [...] Hoje existe a legislação tra- } \\
\text { balhista, que surgiu a partir desse processo histórico, não surgiu } \\
\text { da boa vontade daqueles que estão explorando os trabalhadores, } \\
\text { mas nasceu da própria organização dos trabalhadores, questio- } \\
\text { nando esse modelo de sociedade. }\end{array}$ \\
\hline
\end{tabular}

FONTE: Elaborado pela autoria. 


\section{Considerações finais}

Ao concluirmos este trabalho e tendo presente a realidade social de destruição dos direitos sociais conquistados com muita luta pelas classes trabalhadoras, nossa pesquisa trouxe como um de seus achados fundamentais, o repensar a função social da filosofia e o seu lugar na educação em específico no Proeja. $\mathrm{Se}$, desde o seu nascimento, a filosofia se caracterizou como um distanciar-se do mundo para pensá-lo de forma abstrata, a partir dos filósofos da práxis, ela adquiriu outra dimensão, não apenas a de refletir sobre o mundo, mas de engajar-se em sua transformação, ou seja, converteu-se em uma práxis. Em síntese, a pesquisa revelou que ao problematizarem os temas geradores da realidade social, entre eles, a terceirização e o desemprego, desenvolveram uma práxis filosófica, que efetivamente contribuiu para um processo de formação humana integral. Entretanto, a práxis filosófica se efetivou não em todas as disciplinas que compuseram a pesquisa de campo, mas apenas nos componentes curriculares de "Filosofia II"; "Sociologia II"; "Direito Aplicado"; "Psicologia do Trabalho" e "História III". No entanto, ao afirmarmos a necessidade de uma práxis filosófica no Proeja, não significa a defesa da ideia de que a filosofia deva figurar como um tema transversal ao currículo do Ensino Médio, como proposto pela reforma do Ensino Médio do governo federal. Pelo contrário, compreendemos que ela, (a filosofia) deve ocupar seu lugar no currículo, pois tem uma importância fundamental no processo de desenvolvimento de um pensar reflexivo e crítico sobre a realidade social e pessoal, contribuindo em conjunto com as demais para um autêntico processo de formação humana integral. E, por fim, cabe destacar que a filosofia como práxis só conseguiu realizar a dimensão integradora entre as diversas áreas de conhecimento, por ser fundamento da ciência e seu guia, ao mesmo tempo, em que é por essa guiada.

\section{REFERÊNCIAS}

ANTUNES, R.; DRUCK, G. A epidemia da terceirização. In: ANTUNES, R. (Org.). Riqueza e miséria do trabalho no Brasil III. 1. ed. São Paulo: Boitempo, 2014.

BARDIN, L. Análise de conteúdo. São Paulo: Edições 70, 1977.

FRANCO, M. L. P. B. Análise de conteúdo. 2. ed. Brasília: Líber Livro Editora, 2005. 
FREIRE, P. Pedagogia do oprimido. Rio de Janeiro: Paz e Terra, 1987.

FREIRE, P. Política e educação: ensaios. São Paulo: Cortez, 1993/1997.

FREIRE, P. Conscientização: teoria e prática da libertação. São Paulo: Centauro, 2001.

FREIRE, P. Pedagogia da autonomia: saberes necessários à prática educativa. São Paulo: Paz e Terra, 2013.

GRAMSCI, A. Concepção dialética da história. 2. ed. Rio de Janeiro: Civilização Brasileira, 1978.

GRAMSCI, A. Os intelectuais e a organização da cultura. 4. ed. Tradução de Carlos Nelson Coutinho. Rio de Janeiro: Civilização Brasileira, 1982.

GRAMSCI, A. Americanismo e fordismo. São Paulo: Hedra, 2008.

LAVILLE, C.; DIONNE, J. A construção do saber: manual de metodologia da pesquisa em ciências humanas. Porto Alegre: Artmed; Belo Horizonte: Editora UFMG, 1999.

LUKÁCS, G. Ontologia do ser social: os princípios ontológicos fundamentais de Marx. Trad. de Carlos Nelson Coutinho. São Paulo: Ciências Humanas, 1979.

MARX, K. Os manuscritos econômico-filosóficos. Trad. Alex Martins. São Paulo: Martin Claret, 2002.

MARX, K. O capital: crítica da economia política. Livro I. O processo de produção do capital. Tradução de Rubens Enderle. São Paulo: Boitempo, 2013.

MARX, K. Cadernos de Paris: manuscritos econômico-filosóficos. 1. ed. São Paulo: Expresso Popular, 2015.

MARX, K.; ENGELS, F. A ideologia alemã. 1. ed. Tradução de Álvaro Pina. São Paulo: Expressão Popular, 2009.

VÁZQUES, A. S. Filosofia e circunstância. Rio de Janeiro: Civilização Brasileira, 2002.

Texto recebido em 17 de julho de 2017. Texto aprovado em 05 de fevereiro de 2018. 